\title{
Assessment of Stroke Knowledge Among a Sample of Iraqi Adults Individuals Attending AL- Sheikh Zayed Hospital in Baghdad City
}

\author{
Mohmmed Qassim Baktash ${ }^{1, *}$, Moatz Majeed Ali ${ }^{2}$, Aqeel Abdul Azeez Hasan ${ }^{3}$ and
}

\author{
Abdul Aziz Ahmed Aziz ${ }^{4}$ \\ ${ }^{1}$ University of Telafer/ College of Nursing, PhD. CHN \\ ${ }^{2}$ Al-Russafa Health Directorate, Baghdad Governorate, Ministry of Health and Environment, M.B.CH. B, C.A.B.P \\ ${ }^{3}$ Al-Russafa Health Directorate, Baghdad Governorate, Ministry of Health and Environment, PhD \\ ${ }^{4}$ University of Telafer, Ministry of Higher Education and scientific Research \\ "Corresponding author. Email: mohammed.q.baktash@uotelafer.edu.iq
}

\begin{abstract}
Background and Purpose: Stroke is the third leading cause of death in Iraq exceeding only by coronary heart disease and war related death. This study aims to assess the stroke knowledge among a sample of Iraqi adult individuals attending Al-Sheikh Zayed hospital in Baghdad city. Methods: This study employed a cross-sectional design for period from $1^{\text {st }}$ October 2020 to $1^{\text {st }}$ April 2021. A purposive sample of (200) adult individuals Attending AL- Sheikh Zayed hospital in Baghdad City are conveniently selected and included in the study. The data is collected with interview method by using Stroke Knowledge Test Scale. Results: The results of the study shows that the majority of the study participants are adults between age of 25-35-year-old (31\%), male (52\%), married (60\%), smokers (49\%), and having sedentary lifestyle (69\%). Family history of stroke, hypertension and diabetes mellitus are the common clinical history that is diagnosed among over $(50 \%)$ of participants. The results also reveal the stroke knowledge is low to moderate over (96\%) of participants. Pearson correlation coefficient proved that there is a significant positive association between stroke knowledge and level of education, family history of stroke, high cholesterol level, hypertension and cardiovascular disease. Conversely, there is a significant negative correlation between stroke knowledge and each of age and smoking. Conclusion: This study is clinically significant, since it's highlighted the level of stroke related knowledge among a sample of Iraqi adult's people. As well as, the study revealed strong association between stroke knowledge and number of demographical, behavioral and clinical characteristics.
\end{abstract}

Keywords: Stroke, Knowledge.

\section{INTRODUCTION}

The World Stroke Organization; signaled that more than 13 million new cases of stroke are diagnosis annually worldwide [1]. The seriousness of stroke emerges not only out of its ability to kills its victims (the second leading cause of death worldwide), but also to its capacity to make permanent disability among its survivors. Concerning economic burden, it's estimated that each stroke case cost approximately 140,000 United State dollars $[2,3]$. Stroke is the third leading cause of death in Iraq exceeding only by coronary heart disease and war related death. The latest report published by World Health Organization (WHO) in 2018 indicated that stroke related death in Iraq reached 11,205 or $6.53 \%$ of total deaths. The age adjusted Death Rate is 75.79 per 100,000 of population ranks Iraq \#85 in the world [4]. Aging is the strongest determinant of stroke (approximately, over $(75 \%)$ of stroke cases worldwide appear in individuals age more than 65 years) [5]. However, stroke is amo 
ng a limited number of preventable diseases. Studies reveals that there are more than 10 modifiable risk factors could be used to eliminate over $(80 \%)$ of stroke causes $[2,3]$.

Finally, despite the fact that the stroke is a major public health concern, the stroke incidence is continuing to increase every year worldwide [6, 7]. This fact illustrates the importance of enhancing stroke primary prevention programs.

Knowledge is one of the oldest primary prevention strategies. Many studies hypothesized that improving peoples' awareness about stroke will lead them to adopt a lifestyle that minimizes their stroke risks [8-10].

Sullivan and Katajamaki [11] in their study of Stroke education performed a literature review about stroke knowledge that involved articles from 1994 to 2007. This review indicated that stroke knowledge is relatively weak in a wide range of the samples.

In this study, we performed a review to the stroke knowledge studies conducted from 2007 to 2018. Sixteen articles were found in the review, the analysis of articles indicated that (a) stroke knowledge is poor among most of the participants in these studies. (b) most studies used the cross-sectional design with an interview as means for data collection. (c) Some studies attempted to develop specific educational programs to increase public awareness about stroke. Table 1 summarizes the stroke knowledge studies, which have been conducted in the last ten years.

Table 1. Summary of Stroke Knowledge Studies in the Last Ten Years.

\begin{tabular}{|c|c|c|c|}
\hline Authors & Sample & Methods & Finding(s) \\
\hline Sit, Yip [10] & adults $(n=147)$ & Quasi-Experimental & $\begin{array}{l}\text { The study indicated positive changes in stroke } \\
\text { knowledge among the experimental group }\end{array}$ \\
\hline $\begin{array}{l}\text { Gibson and } \\
\text { Watkins [12] }\end{array}$ & $\begin{array}{l}\text { Vascular } \\
\text { surgical patients }\end{array}$ & Qualitative Study & $\begin{array}{l}\text { The study revealed that patients use both } \\
\text { formal and informal knowledge in decision }\end{array}$ \\
\hline Yang, Zheng [13] & Adult $(\mathrm{n}=1500)$ & Cross-sectional design & $\begin{array}{l}\text { The study indicated that the community } \\
\text { residents lacked the awareness of stroke risk }\end{array}$ \\
\hline $\begin{array}{l}\text { Dombrowski, } \\
\text { Mackintosh [14] }\end{array}$ & $\begin{array}{l}\text { Stroke patient's } \\
(\mathrm{n}=19)\end{array}$ & $\begin{array}{l}\text { semi-structured } \\
\text { interviews }\end{array}$ & $\begin{array}{l}\text { The study aimed to measure the changes in } \\
\text { the stroke knowledge from } 2010 \text { to } 2015 \text {. The } \\
\text { majority of participants reported no changes }\end{array}$ \\
\hline $\begin{array}{l}\text { Haitham, Amr } \\
{[15]}\end{array}$ & adults $(n=368)$ & cross-sectional design & $\begin{array}{l}\text { Knowledge of stroke appeared poor among } \\
\text { participants. }\end{array}$ \\
\hline Zhao, Zhou [16] & $\begin{array}{l}\text { Individuals with } \\
\text { TIA }(n=355)\end{array}$ & $\begin{array}{l}\text { Repeated Measure } \\
\text { Design }\end{array}$ & $\begin{array}{l}\text { The study revealed that the TIA patients with } \\
\text { subsequent stroke demonstrated a higher } \\
\text { awareness rate of the caution signs of stroke. }\end{array}$ \\
\hline Yang, Zhang [17] & $\begin{array}{l}\text { General } \\
\text { physicians } \\
\text { (GPs) and }\end{array}$ & cross-sectional study & $\begin{array}{l}\text { Community GPs and nurses in the urban } \\
\text { districts of Chongqing lacked to the } \\
\text { knowledge of stroke. }\end{array}$ \\
\hline $\begin{array}{l}\text { Aycock, } \\
\text { Kirkendoll [18] }\end{array}$ & $\begin{array}{l}\text { African } \\
\text { Americans }\end{array}$ & Cross-sectional study & $\begin{array}{l}\text { There were no meaningful variations between } \\
\text { groups in stroke knowledge. }\end{array}$ \\
\hline $\begin{array}{l}\text { Kaddumukasa, } \\
\text { Kayima [19] }\end{array}$ & adult $(n=377)$ & cross-sectional survey & $\begin{array}{l}\text { Stroke knowledge was inadequate among } \\
\text { participants }\end{array}$ \\
\hline $\begin{array}{l}\text { Riechel, Alegiani } \\
\text { [20] }\end{array}$ & $\begin{array}{l}\text { Cerebrovascular } \\
\text { patients }\end{array}$ & survey & The level of stroke risk knowledge was low \\
\hline $\begin{array}{l}\text { Ishigami, Yokota } \\
\text { [21] }\end{array}$ & $\begin{array}{l}\text { Children and } \\
\text { Parents }\end{array}$ & Quasi-Experimental & Stroke education aid was effective. \\
\hline $\begin{array}{l}\text { Aldebasi, Alamri } \\
\text { [22] }\end{array}$ & $\begin{array}{l}\text { adult }(\mathrm{n}=2021) \\
\text { Saudi subjects }\end{array}$ & cross-sectional study & $\begin{array}{l}\text { Knowledge was inadequate among the } \\
\text { majority of participants. }\end{array}$ \\
\hline $\begin{array}{l}\text { Metias, Eisenberg } \\
\text { [23] }\end{array}$ & adults $(n=1025)$ & survey & $\begin{array}{l}\text { Stroke knowledge has continued stable with } \\
\text { no changes overtime. }\end{array}$ \\
\hline Farrag, Oraby [24] & $\begin{array}{l}\text { Adult }(n=1154) \\
\text { form Egypt }\end{array}$ & cross-sectional study & $\begin{array}{l}\text { low public stroke awareness detected among } \\
\text { Egyptians }\end{array}$ \\
\hline
\end{tabular}




\section{METHODOLOGY}

\section{Aim of the Study:}

This study aims to assess the level of stroke knowledge among a sample of Iraqi adult individual attending Al-Sheikh Zayed hospital in Baghdad city

\section{Design of the study:}

This study used a descriptive cross-sectional design period from 1st October 2020 to 1stApril 2021.

\section{Sampling:}

The target population for the study were the Iraqi adult individuals in the chronological age of 25 to 65 years' old who are attending Al-Sheikh Zayed Hospital in Baghdad city. A total of 200 individuals purposively and conveniently selected and participated in the study. The exclusion criteria include those individuals younger than 25 years old or those with pervious history of stroke, and severe physical and psychological impairments.

\section{Instrumentation and data collection:}

The data collecting is performed by using Stroke Knowledge Test Scale (SKTS). This scale consists of two parts designed to measure the level of stroke related knowledge and as follow [25]:

Part I: This part is used to investigate the participant's socio-demographic characteristics, behavioral habits, and clinical history.

Part II: This part is developed to measure the stoke related knowledge. The part consists of 20 items in multiple choice question format. Each question scored in two levels (0) for wrong answer and (1) for wright answer.

After obtaining the informed consent, the data is collected from the participant by interview method. Each interview takes about 4 to 10 minutes.

\section{Validity and reliability of instrument:}

The SKTS demonstrated a good validity and reliability in a number of studies ${ }^{(10,11)}$. However, for the purpose of this study the validity of the questionnaire is tested by presenting it to (10) experts in nursing and medical fields. According to the expert's recommendations some items are changed and other are modified.

The reliability of the instrument is tested by using data from 10 participants who are excluded from the study. Cronbach's alpha is calculated to determine the internal consistency of the study instrument. The overall internal consistency for the questionnaire was acceptable; $\alpha=0.79$.

\section{Data analysis:}

Frequency and percentage are calculated to describe the participants of the study. Pearson correlation coefficient is used to calculate the correlation between stroke knowledge and participant sociodemographic characteristics. Data are analyzed by using Statistical Package for Social Science (SPSS) for Windows Version 25.

\section{RESULTS OF THE STUDY}

The Table 2 indicates that the majority of participants in the study are between age group of 2535 years old $(31 \%)$. The table shows that obesity and overweight is common among (87\%) of participants. Regarding sociodemographic characteristics, the table revels that the majority of participants are male (52\%), married $(60 \%)$ and are graduated (34\%). Concerning behavioral habits, the table shows that the $49 \%$ of participants are currently smokers and $15 \%$ of participants are alcohol drinkers and 69\% of participants having sedentary lifestyle.

\begin{tabular}{|l|c|c|}
\hline Clinical History (Diagnosed with) & F & \% \\
\hline Family history of stroke & 122 & 61 \\
\hline Transient ischemic attack & 62 & 31 \\
\hline Hypercholesterolemia & 74 & 37 \\
\hline Hypertension & 118 & 59 \\
\hline Atrial fibrillation & 42 & 21 \\
\hline Diabetes mellitus & 84 & 42 \\
\hline Cardiovascular disease & 44 & 22 \\
\hline
\end{tabular}

Table 2. The Sociodemographic Characteristics, Behavioural habits of the Study Participants 
M: mean; SD: Standard deviation, F: Frequency, \%: Percentage, BMI: Body Mass Index (<18.5: underweight; 18.5-24.9: normal weight; $25-29.9$ over weight; $\geq 30$ : obesity)

Table 3. The Clinical History the Study Participants

The Table 3 reveals that Family history of stroke, hypertension and diabetes mellitus are the common clinical history that is diagnosed among over $50 \%$ of participants.

Table 4. Level of Stroke Related Knowledge among Participants

\begin{tabular}{|c|c|c|c|c|c|}
\hline \multicolumn{6}{|c|}{ Level of Knowledge } \\
\hline \multicolumn{2}{|c|}{ Low } & \multicolumn{2}{c|}{ Moderate } & \multicolumn{2}{c|}{ High } \\
\hline F & \% & F & \% & F & \% \\
\hline 11 & 56.0 & 80 & 40.0 & 8 & 4.0 \\
\hline
\end{tabular}

F: Frequency, \%: percentage, cut of point: Low (1-6), Moderate (713), High (14-20)

This table demonstrate that the level of stroke knowledge is low to moderate among over $96 \%$ of participants.

Table 5. The Correlation of Stroke Knowledge with the Sociodemographic, Behavioural and Clinical Characteristics of Participants

\begin{tabular}{|l|c|}
\hline Variables & $\begin{array}{c}\text { Knowledge } \\
(\boldsymbol{r})\end{array}$ \\
\hline Age & $-.387^{* *}$ \\
\hline BMI & $-.175^{*}$ \\
\hline Gender & -.072 \\
\hline Marital status & $-.157^{*}$ \\
\hline Level of Education & $.757^{* *}$ \\
\hline Smoking & $-.258^{* *}$ \\
\hline Alcohol drinking & -.111 \\
\hline Exercises & .124 \\
\hline Family history of stroke & $.391^{* *}$ \\
\hline History of transient ischemic & -.009 \\
\hline High Cholesterol & $.256^{* *}$ \\
\hline Hypertension & $.219^{* *}$ \\
\hline Atrial fibrillation & .124 \\
\hline Diabetic & .106 \\
\hline Cardiovascular disease & $.376^{* *}$ \\
\hline
\end{tabular}

r: Pearson correlation coefficient, $* *$. Correlation is significant at the 0.01 level (2-tailed)., *. Correlation is significant at the 0.05 level (2tailed).

The (Table 5) shows the results for Pearson's Correlation Coefficient of the association between stroke knowledge and the sociodemographic, behavioral and clinical characteristics of participants. The table reveals that there is a strong positive correlation between stroke knowledge and each of level of education, family history of stroke, high cholesterol level, hypertension and cardiovascular disease. On the other hand, the table indicates that there is a strong negative correlation between stroke knowledge and each of age and smoking.

\begin{tabular}{|c|c|c|c|}
\hline \multicolumn{2}{|c|}{ Participants Characteristics } & \multicolumn{2}{|c|}{$\begin{array}{l}\text { Sample }(n \\
=200)\end{array}$} \\
\hline Anthropometric & Item & $\mathbf{F}$ & $\%$ \\
\hline \multirow[t]{4}{*}{ Age } & $25-35$ & 62 & 31 \\
\hline & $36-45$ & 42 & 21 \\
\hline & $46-55$ & 46 & 23 \\
\hline & $56-65$ & 50 & 25 \\
\hline \multirow[t]{4}{*}{ BMI } & $<18.5$ & 0 & 00 \\
\hline & $18.5-24.9$ & 44 & 22 \\
\hline & $25-29.9$ & 74 & 37 \\
\hline & $\geq 30$ & 82 & 41 \\
\hline Demographic & Item & $\mathbf{F}$ & $\%$ \\
\hline \multirow{2}{*}{ Gender } & Male & 104 & 52 \\
\hline & Female & 96 & 48 \\
\hline \multirow[t]{4}{*}{ Marital status } & Married & 120 & 60 \\
\hline & Single & 50 & 25 \\
\hline & Divorced & 8 & 4 \\
\hline & Widowed & 22 & 11 \\
\hline \multirow[t]{6}{*}{ Educational level } & Illiterate & 12 & 6 \\
\hline & Write and read & 20 & 10 \\
\hline & Elementary school & 58 & 29 \\
\hline & $\begin{array}{l}\text { Intermediate } \\
\text { school }\end{array}$ & 20 & 10 \\
\hline & High school & 22 & 11 \\
\hline & Graduated & 68 & 34 \\
\hline Behavioral habits & Item & $\mathbf{F}$ & $\%$ \\
\hline \multirow{3}{*}{ Smoking } & Never smoked & 90 & 45 \\
\hline & Currently smoker & 98 & 49 \\
\hline & Stopped smoking & 12 & 6.0 \\
\hline \multirow[t]{2}{*}{ Alcohol drinking } & Never & 170 & 85 \\
\hline & $1-2$ times per day & 30 & 15 \\
\hline \multirow[t]{3}{*}{ Physical activity } & Sedentary (never) & 138 & 69 \\
\hline & 1- 2 days per week & 40 & 20 \\
\hline & 1-5 days per week & 22 & 11 \\
\hline
\end{tabular}

\section{DISCUSSION}

Regarding characteristics of participants, some of the results from (Table 2) were consistent with the Iraqi Ministry of health final report (2016). This report demonstrated the low prevalence of smoking among elderly Iraqi populations, as well as this report proved that hypertension, diabetes mellitus and hypercholesterolemia were most prevalent disease and frequent causes of death among older adults in Iraq [26]

Table 3 manifested that the participant's stroke related knowledge is low to moderate among more than $96 \%$ of them. This result reveals the seriousness of stroke and indicate that Iraqi adult individuals are at risk for this terrible health condition. On the bases of this result, it's essential to develop an educational program to enhance stroke related knowledge among Iraqi adult's individuals in order to ensure healthy lifestyle that prevent stroke based on scientific stroke related knowledge. On the other hand, the result of low level of stroke related knowledge is consistent with a 
number of studies conducted during last 10 years as mentioned in reviewing of literature in (Table 1).

Concerning the correlation between stroke related knowledge and participant's sociodemographic characteristics, behavioural habits and clinical history, the table 4 shows that there is a strong positive correlation between stroke knowledge and each of level of education, family history of stroke, high cholesterol level, hypertension and cardiovascular disease. This indicate that the higher educational level, the higher stroke knowledge. The stroke knowledge is also increase among those participants who are having a family history of stroke and those with hypercholesterolemia, hypertension and cardiovascular disease. This result may signify the importance of the clinical history in improving stroke related knowledge. On the other hand, the table 4 indicates that there is a strong negative correlation between stroke knowledge and each of smoking and age. This reveals that the older individuals and those who are currently smokers having low level of stroke knowledge.

\section{CONCLUSION}

Finally, the results of this study can be clinically important, since it highlighted that the stroke related knowledge is low to moderate among Iraqi adult individuals. The study also highlighted the correlation between stroke knowledge and number of individual's characteristics this information could be used to develop an educational program to prevent stroke and adopting healthy lifestyle.

\section{RECOMMENDATIONS:}

Based on the study results and its interpretation this study recommends the following:

1. Conducting additional studies to measure the level of stroke related knowledge among Iraqi People.

2. Develop an educational program to improve stroke related knowledge among Iraqi Population.

\section{REFERENCES}

[1] Lindsay, M.P., et al., World stroke organization (WSO): global stroke fact sheet 2019. 2019, SAGE Publications Sage UK: London, England.

[2] Feigin., V. and R. Krishnamurthi, Epidemiology of Stroke, in Oxford Textbook of Stroke and Cerebrovascular Disease, B. Norrving, Editor. 2014, Oxford University Press: United States of America. p. 1.

[3] Markus, H., A. Pereira, and G. Cloud, Stroke Medicine. 2 ed. Oxford Specialist Handbooks in
Neurology 2017, United States of America: Oxford University Press. 1.

[4] World Life Expectancy. Stroke in Iraq. 2019 January 09, 2019]; Available from: https://www.worldlifeexpectancy.com/iraqstroke.

[5] Anna, M., Cervantes-Arslanian., and S. Seshadri, Primary Prevention of Stroke, in Oxford Textbook of Stroke and Cerebrovascular Disease, B. Norrving, Editor. 2014, Oxford University Press: United States of America p. 256-264.

[6] Benjamin, E.J., et al., Heart disease and stroke statistics-2017 update: a report from the American Heart Association. Circulation, 2017. 135(10): p. e146-e603.

[7] Corcoran, N., Stroke 5: health promotion for primary stroke prevention. Nursing Times [online], 2017. 115(3): p. 53-56.

[8] Newey, C.R., et al., A new strategy in neurocritical care nurse continuing stroke education: A hybrid simulation pilot study. Electronic Physician, 2017. 9(5): p. 4255-4260.

[9] Pratt, C.A., et al., Stroke knowledge and barriers to stroke prevention among African Americans: implications for health communication. J Health Commun, 2003. 8(4): p. 369-81.

[10] Sit, J.W.H., et al., A quasi-experimental study on a community-based stroke prevention programme for clients with minor stroke. Journal of Clinical Nursing, 2007. 16(2): p. 272-281.

[11] Sullivan, K.A. and A. Katajamaki, Stroke education: promising effects on the health beliefs of those at risk. Top Stroke Rehabil, 2009. 16(5): p. 377-87.

[12] Gibson, J.M. and C.L. Watkins, The use of formal and informal knowledge sources in patients' treatment decisions in secondary stroke prevention: qualitative study. Health Expect, 2013. 16(3): p. e13-23.

[13] Yang, J., et al., A survey of the perceived risk for stroke among community residents in western urban China. PLoS One, 2013. 8(9): p. e73578.

[14] Dombrowski, S.U., et al., The impact of the UK 'Act FAST' stroke awareness campaign: content analysis of patients, witness and primary care clinicians' perceptions. BMC Public Health, 2013. 13: p. 915.

[15] Haitham, H., et al., Knowledge and Attitudes towards Stroke among Workers in Two University Hospitals. Egyptian Journal of Neurology, Psychiatry \& Neurosurgery, 2013. 50(1): p. 49-54.

[16] Zhao, J., et al., Differences in the knowledge and compliance with secondary prevention of stroke 
between transient ischaemic attack patients with and without subsequent stroke. J Clin Nurs, 2014. 23(19-20): p. 2939-48.

[17] Yang, J., et al., Knowledge of Community General Practitioners and Nurses on Pre-Hospital Stroke Prevention and Treatment in Chongqing, China. PLoS One, 2015. 10(9): p. e0138476.

[18] Aycock, D.M., et al., Family history of stroke among African Americans and its association with riskfactors, knowledge, perceptions, and exercise. J Cardiovasc Nurs, 2015. 30(2): p. E1-6.

[19] Kaddumukasa, M., et al., Knowledge, attitudes and perceptions of stroke: a cross-sectional survey in rural and urban Uganda. BMC Res Notes, 2015. 8: p. 819.

[20] Riechel, C., et al., Subjective and objective knowledge and decisional role preferences in cerebrovascular patients compared to controls. Patient Prefer Adherence, 2016. 10: p. 1453-60.

[21] Ishigami, A., et al., Delivering Knowledge of Stroke to Parents Through Their Children Using a Manga for Stroke Education in Elementary School. J Stroke Cerebrovasc Dis, 2017. 26(2): p. 431-437.

[22] Aldebasi, K.A., et al., Knowledge, Attitude and Practicetowards Stroke Risk Factors and Warning Symptoms in Saudi Arabia, 2017. Egyptian Journal of Hospital Medicine, 2017. 69(3).

[23] Metias, M.M., et al., Public health campaigns and their effect on stroke knowledge in a high-risk urban population: A five-year study. Vascular, 2017. 25(5): p. 497-503.

[24] Farrag, M.A., et al., Public stroke knowledge, awareness, and response to acute stroke: Multicenter study from 4 Egyptian governorates. J Neurol Sci, 2018. 384: p. 46-49.

[25] Sullivan, K. and N.J. Dunton, Development and validation of the stroke knowledge test. Topics in stroke rehabilitation, 2004. 11(3): p. 19-28.

[26] Ministry of Health, Annual Statistical Report / 2016. Baghdad, Iraq: Iraqi ministry of Health / environment and Iraqi National Library and Archives, 2017 